\title{
PROCESSOS BIOTECNOLÓGICOS PARA A MELHORIA DE QUALIDADE DO CAFÉ CONILON, COM E SEM MICRORGANISMOS STARTERS
}

\author{
Dério Brioschi Junior ${ }^{1}$ \\ Luiz Henrique Bozzi Pimenta de Sousa ${ }^{2}$ \\ João Paulo Pereira Marcate ${ }^{3}$ \\ Evandro de Andrade Siqueira ${ }^{4}$ \\ Deusélio Bassini Fioresi ${ }^{5}$ \\ Rogério Carvalho Guarçoni ${ }^{6}$ \\ Fabiana Carvalho Rodrigues ${ }^{7}$ \\ Lucas Louzada Pereira ${ }^{8}$
}

Resumo: O objetivo deste trabalho foi avaliar o potencial de diferentes métodos de fermentação sobre o café da variedade conilon, com e sem culturas starters de S. cerevisiae sp., juntamente a métodos já consolidados para a produção de café arábica por via-úmida. Para a realização do experimento, o café foi colhido de forma seletiva e processado no mesmo dia, retirando os frutos secos, boias e verdes. Foram realizados seis tratamentos distintos com cinco repetições onde: os tratamentos "Washed", "Fully washed with yeasts", "Yeasts with water" e "Yeasts waterless" foram avaliados em um tempo de fermentação 24 horas, além de "cereja descascado - semi-dry" e "natural" que não sofreram fermentação. As amostras foram avaliadas por seis juízes profissionais (experts) em análise sensorial de café. O protocolo de provas contém 10 atributos, para análise dos resultados foram utilizados apenas os seguintes atributos: Equilibrio, Conjunto Uniformidade, Limpeza e Qualidade Global. Os resultados indicam que as inoculações de culturas starters apresentaram-se como melhores tratamentos quando comparados aos tratamentos "cereja descascado" e "natural".

Palavras-chave: Processamento via-úmida; Sacaromices cerevisiae sp.; Fermentação; Café conilon.

\footnotetext{
1 Departamento de Ciência dos Alimentos/Instituto Federal do Espírito Santo, Brasil. E-mail: derio.brioschi@outlook.com.

2 Departamento de Ciência dos Alimentos/Instituto Federal do Espírito Santo, Brasil. E-mail: luizhenriquebozzi@hotmail.com.

3 Departamento de Ciência dos Alimentos/Instituto Federal do Espírito Santo, Brasil. E-mail: joãopaulomarcate@hotmail.com.

4 Departamento de Ciência dos Alimentos/Instituto Federal do Espírito Santo, Brasil. E-mail: evandro.siqueira@ifes.edu.br.

5 Departamento de Ciência dos Alimentos/Instituto Federal do Espírito Santo, Brasil. E-mail: deuselio.fioresi@ifes.edu.br.

6 Instituto Capixaba de Pesquisa/Assistência Técnica e Extensão Rural (INCAPER). Centro Regional de Desenvolvimento Rural, Brasil. E-mail: rogerio.guarconi@incaper.es.gov.br.

7 Departamento de Ciência dos Alimentos/Instituto Federal do Espírito Santo, Brasil. E-mail: fabiana.rodrigues@ifes.edu.br.

8 Departamento de Ciência dos Alimentos/Instituto Federal do Espírito Santo, Brasil. E-mail: lucas.pereira@ifes.edu.br.
} 